\title{
Wine Authenticity and Traceability with the Use of FT-IR
}

\author{
Marianthi Basalekou ${ }^{1, *}$, Christos Pappas ${ }^{2}$, Petros A. Tarantilis ${ }^{2}\left(\mathbb{D}\right.$ and Stamatina Kallithraka ${ }^{1}$ \\ 1 Department of Food Science \& Human Nutrition, Laboratory of Oenology, \\ Agricultural University of Athens, 75 Iera Odos, 11855 Athens, Greece; stamatina@aua.gr \\ 2 Department of Food Science \& Human Nutrition, Laboratory of General Chemistry, \\ Agricultural University of Athens, 75 Iera Odos, 11855 Athens, Greece; chrispap@aua.gr (C.P.); \\ ptara@aua.gr (P.A.T.) \\ * Correspondence: marianthi@aua.gr
}

Received: 29 February 2020; Accepted: 26 April 2020; Published: 8 May 2020

\begin{abstract}
Fourier transform infrared spectroscopy (FT-IR) has gained popularity in the wine sector due to its simplicity and ability to provide a wine's fingerprint. For this reason, it is often used for authentication and traceability purposes with more than satisfactory results. In this review, an outline of the reasons why authenticity and traceability are important to the wine sector is given, along with a brief overview of the analytical methods used for their attainment; statistical issues and compounds, on which authentication usually is based, are discussed. Moreover, insight on the mode of action of FT-IR is given, along with successful examples from its use in different areas of interest for classification. Finally, prospects and challenges for suggested future research are given. For more accurate and effective analyses, the construction of a large database consisting of wines from different regions, varieties and winemaking protocols is suggested.
\end{abstract}

Keywords: FT-IR; wine; authentication; traceability; origin; typicity; aging

\section{Introduction}

Wine is a product that can be characterized both as a commodity but also as a luxury, depending on its price [1]. To satisfy shifting consumer behavior, the wine sector offers a wide range of wine prices, starting from low priced affordable wines and reaching such high values in the case of premium wines, that the latter can even be considered as an investment [2]. Especially for these fine wines, quality is of the outmost importance, while notions such as safety and also integrity are equally necessary for their price justification. Indeed, a premium wine should first of all be safe to consume, present high-quality characteristics and have the means to communicate its superiority [3]. This is difficult to achieve; hence, the consumer or buyer must either rely on a wine's reputation (market success, connoisseur reviews, absence of negative reviews about its authenticity or safety, etc.) and make a purchase based on a wine brand or label, or on the laws protecting geographical indications and traditional specialties, which mark the wines with a special logo to help verify their authenticity [4]. Geographical indication authenticates the wine in terms of location of the vineyards used in winemaking, but also sets a number of regulations regarding the wine production itself, such as grape variety used in winemaking, aging or not, use of barrel or not, etc. This set of regulations guarantees that the wine was produced in the most favorable way in order to reach optimum quality. Geographical classification is used throughout the wine world, with regulations based on the same type of parameters, i.e., type of grapes, aging and use of oak, except in the case of Bordeaux, one of the most prestigious and high-quality wine regions, where the ranking of the wines in "crus" is based on their reputation and trading price in 1855, the year the classification was established [5]. 
Whatever type of classification is used to differentiate wines, it is based on their unique characteristics, imparted to them either by the place of origin, a specific type of grape variety or a specific winemaking protocol; thus there is a need for traceability in order to verify the steps followed during wine production and also for authentication in order to eliminate the possibility of adulteration, which, especially in the fine wine market, has been the source of many types of fraud, including dilution, mislabeling, use of unauthorized grape varieties or barrel wood sources, etc. [6].

\section{Authentication and Traceability in the Wine Sector}

\subsection{Traceability}

In the last years, the price of wine became a less reliable attribute in defining the overall quality of a product and consumers started considering alternative factors called credence attributes as more important [7]. This, together with the need of millennials for cleaner, sustainable and ecofriendly products, led to a series of changes in the wine sector that ultimately made wineries impose strict controls in the quest for higher quality. Traceability naturally became important as it is a quality assurance system, able to verify the origin and all production steps and processes performed from grape to bottle. Different systems have been used since traceability has been introduced in the 1990s, but it is widely and generally more successfully used by large companies with aligned supply chains which are more likely to store production information or use automated systems [8]. Indeed, "boutique" or medium-sized wineries without privately owned vineyards face difficulties gathering all the relevant information as different people are in charge of different processes. For example, information such as parcel location, grape variety, irrigation, time of pruning, use of fertilizers and/or fungicides, etc., come from the grape producer, while the winemaker is responsible for collecting data concerning all the details of wine production, such as the winemaking protocol implemented (all winemaking procedures such as maceration, clarification, racking, barrel aging and blending, among others), any types of additives used, as well as dates of all operations performed, including dates and details of grape receival. Finally, the distributor is responsible for bottle storage information, and is the one who will provide data on dates and times of dispatching and possible receivals in case the wines are returned [8].

Different tools are available to make data collection easier, such as computer software or digital applications, but the biggest breakthrough in traceability in the wine supply chain comes from the ability to monitor grape cultivation parameters using remote sensing technologies such as the Global Positioning System/Geographic Information System (GPS/GIS). Precision viticulture can help grape growers manage the variability of different factors that affect grape quality such as soil characteristics, topography, yield and even pests and diseases [9]. Then, not only there can be improvements to quality, but all data are simultaneously gathered, leaving less room for human errors.

\subsection{Authentication}

Even if all traceability procedures, including taking records, gathering data, contracts and all details regarding grape cultivation and production are followed to the letter, wine identity and provenance need to somehow be guaranteed by analyses on the final product, in order to eliminate unintentional mistakes such as mislabeling. For this reason, wine origin and composition must be verified using strict guidelines that are often set by national authorities.

\subsubsection{Origin Authentication}

Origin authentication is essential as the quality of grapes, and by extension, the quality of wine, is directly affected by the specific climatic and topographic conditions of a place. Moreover, as mentioned earlier, many countries have set "geographical indications" or "denominations of origin", recognizing this way that location directly influences the final product [10]. Between these denominations, some are set based on traditional practices, such as the case of the Greek Retsina wine, which underlines the fact that not just the geographical origin, but the "terroir", i.e., not only the 
location, but also procedures typically used at a certain place, can impart specific characteristics to a wine. In order to verify origin in terms of geography, authentication analyses are based on unique compounds called chemical "markers" that can be used as indicators of a place, provided that they can be found both in the soil and the grapes themselves as well. For this reason, many studies are based on the trace element composition of wine [11-13].

\subsubsection{Identity Authentication}

In order to authenticate a wine's identity, the term identity should first of all be defined. In most cases, it is not clear which criteria are applied in order to declare a wine representative of its category, or typical of its variety [14]. Naturally, the grape variety, the cultivation area, the winemaking protocol, the alcohol level and potential barrel aging between others all characterize a wine, outlining its unique profile and making up its identity. However, a wine's sensory character, or more specifically, its "typicity", i.e., if the wine can be characterized as a typical example of a wine made from a given grape variety, is difficult to be objectively measured. For example, typicity cannot be defined by analysis of volatile compounds; the wine needs to be evaluated by a trained panel of professionals instead. Given that wine is a product with a highly complex matrix, and due to the fact that sensory attributes can be very difficult not only to detect but to describe using a fixed vocabulary, common to all wine tasting panels, fully characterizing a wine's sensory character can be very difficult [15]. Moreover, identity authentication may involve analyses regarding not only the parameters mentioned earlier, but additional ones that either have to do with the type of production and are of interest, for example, due to economic reasons (i.e., analyses to identify the type of method followed in sparkling wine production), due to health issues (i.e., if allergens were used during wine production, such as isinglass) or due to current day interests such as concern over whether a certain wine is organic, vegan, etc. For some, strict laws are imposed, as in the case of the EU demanding the use of oak chips to be reported on the label, or woods other than oak and chestnut wood to not be used for wine aging [16]. Maturation in stainless steel tanks or in contact with some type of wood, mostly oak, has been the focus of many studies, since barrel aging can add value to a wine, although the time the wine needs to spend in the cellar plus the price of a wooden barrel increases the cost of production.

It is essential, therefore, to include all these parameters when authenticating a wine. As with origin, identity authentication is based on identification of the composition of the wine, using either marker compounds that are characteristic and unique for each parameter, or comparisons with known and authentic samples.

\section{Authentication and Traceability Methods}

\subsection{Authentication and Traceability Methods}

Many methods and techniques are used for the traceability and authentication of wines, based on the nature of the target compounds. Among the most commonly used techniques in wine research laboratories, high pressure liquid chromatography (HPLC) and gas chromatography (GC) are routinely used for qualitative and quantitative analyses of chemical compounds present in wine, and also for the development of its overall profile. Chemical groups of interest in the case of HPLC are mostly the phenolic compounds $[17,18]$. HPLC is a robust and reproducible technique, although it involves many preparatory steps, making the analysis quite laborious [18]. GC is equally robust, versatile and of high sensitivity, and investigates the origin of the wine through the analysis of its volatile profile or deals with its identity through the determination of volatile marker compounds [14]. One of the key advantages of GC is that it can detect volatiles present in wood; thus it can verify barrel aging [19].

Other techniques that have been successfully used include isotope ratio mass spectroscopy (IRMS) [20], nuclear magnetic resonance (NMR)-based techniques [21], inductively coupled plasma mass spectrometry (ICP-MS) [22,23] and also DNA techniques and sensor technology [18,24]. Over the past twenty years, metabolomic approaches started also becoming more and more appealing, as they 
offered a wide range of authentication possibilities. These techniques examine changes on a set of metabolites, with weights less than $1500 \mathrm{Da}$, which can be found in grapes and wines as well [25]. However, most of these techniques are cost effective, with high detection limits, or require sophisticated preparation steps and specialized operators, which makes them less appealing for fast and precise analysis in wine.

Spectroscopy offers a set of techniques, such as near infrared (NIR), mid-infrared (MIR), Raman and hyperspectral imaging that have gained a lot of attention from the research community during the past few years. Specifically, in wine authentication and traceability, they can offer more than satisfactory results while they are able to also produce quantification models for a wide set of chemical compounds [26-28]. Spectroscopy offers simplicity, is fast and cost effective, and most importantly, requires few, if any, preparatory steps; it can produce results through nondestructive measurements on a small amount of sample. Between these techniques, Fourier transform infrared spectroscopy (FT-IR) is gaining more attention regarding wine analysis, given its higher selectivity and performance when compared to the other techniques.

\subsection{Chemometry}

In general, chemometrics are essential for authentication and traceability purposes as they present a solution in handling and combining complex analysis results. Indeed, in the absence of unique compounds that could potentially be used as traceability or authenticity markers for a specific sample, various types of analysis results must be combined in order for a pattern to be revealed. Algorithms can be developed following several techniques, such as principal component analysis (PCA) or cluster analysis, canonical, linear and factorial discriminant analysis, soft independent modeling by class analogy (SIMCA), artificial neural networks and support vector machines [29-32].The most often used methods are PCA, linear discriminant analysis (LDA), partial least squares (PLS) regression analysis and SIMCA. All these methods aim to treat the data in the most efficient way in order to model the analyzed samples according to a particular parameter based on similarities and differences resulting from the sample's spectra or polyphenolic profile, revealing groups of categorized samples [33]. The methods used for categorization can be separated into supervised and unsupervised methods depending on whether the groups result from combining analysis results without setting corresponding output variables beforehand (for example, a PCA plot (unsupervised technique) reveals groups that may have been formed by the samples, while an LDA plot depicts the groups the user has already set as classes) and to what extent the samples fall correctly into each group [33].

\subsection{Compounds of Interest}

Since the group of polyphenols is the most important group both in grapes and wines, most of the analyses performed for authentication purposes focus on anthocyanins, flavonols, flavanols and generally on phenol combinations.

For example, anthocyanins, which are colored pigments responsible for the color of red grapes and wines, are not present in white grapes or wines, so their presence can obviously be an indicator of variety color. It has also been proposed that red grape varieties can be discriminated based on their anthocyanic fingerprint, so all anthocyanins, especially the acetylated ones, have been analyzed, and with the use of PCA, several varieties have been successfully discriminated [29,34,35]. Flavanols are also used as varietal markers [36], while flavanols have been successful in determining both variety and origin [37]. Nonflavonoids were also used in wine origin discrimination [38], and a broad combination of phenolics can be used to classify wines not only based on origin but also on variety as well [39]. Tannins are commonly used for identification of wood contact, as hydrolyzable tannins are only present in barrels or their alternatives (chips, cubes, sticks, etc.) and cannot be found in grapes [40]. Finally, volatile compounds have been used for vintage authentication [41,42] and aging [43].

Naturally, many other chemical compounds outside the polyphenol group can be used for authentication purposes, such as aminoacids, proteins or minerals [41]. Indeed, trace elements reflect 
the soil geochemistry, and have the ability to move from soil to grape and from grape to wine. In particular, the group of lanthanides-or rare earth elements-are very appealing due to their chemical similarity and the fact that they remain unaltered passing from soil to the plant, which establishes them as powerful geochemical markers [44,45]. In a recent study, 10 minerals were needed to help discriminate Chinese wines from different regions; however, most times statistical approaches required more than 10 compounds in order to create a profile of the content of trace metals or the elements' fingerprint [46]. Trace elements are used as chemical markers since passing from soil to grape and then to wine does not affect them; however, wine fining can modify the resulting fingerprint by causing fractionation, an issue addressed by several authors $[45,47,48]$. Except for the use of trace elements, the distribution of stable isotopes has been studied; however, this type of analysis requires univariate comparison with a databank of authentic samples, such as the databank set up by the European Union [49]. However, compound selection poses many limitations and some serious considerations, as rarely a single group of chemical compounds can be responsible for a complete classification. For this reason, profiles constructed by untargeted analyses provide a more complete way of describing a sample and consequently classifying it. For this type of analysis, vibrational spectroscopy coupled with chemometrics is ideal, as it helps obtain structural characteristics and provide the sample's "fingerprint". This gives the researcher the great advantage to use information recorded in a sample's spectra that not only comes as a result of chemicals that have not been quantified, but also information resulting from unidentified compounds whose impact on the classification itself could not be individually evaluated beforehand. For these types of analyses, multivariate data analysis (MDA) is essential, as it will be the tool needed to establish the link between the analytical instrument and the parameter set for classification. In the case of origin classification, for example, if the components established from statistical analysis have enough discriminatory power, MDA will help detect a pattern or a fingerprint, based on which the geographical origin will be discriminated [50].

\section{FT-IR Spectroscopy}

In FT-IR spectroscopy, infrared radiation is emitted by a source and passed through a sample via a Michelson interferometer (Figure 1). The interferometer splits the beam of light, transmitting one-half and reflecting the other. With the help of two mirrors, one fixed and one moveable, the split beams are reflected back together, producing interference fringes. The produced "interferogram", which measures the change in radiation intensity, is recorded by a detector as a signal; then it is amplified, and finally it is transferred to a computer in which Fourier transform is carried out and the interferogram is converted into a spectrum [51].

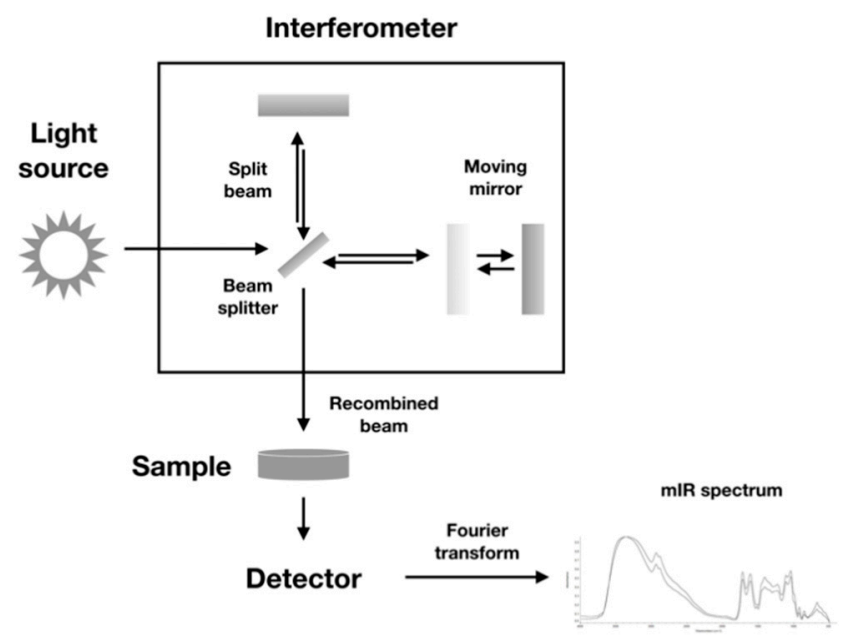

Figure 1. Schematic diagram of a typical FT-IR setup and a Michelson interferometer. 
The spectrum is a plot of the measured IR intensity versus the wavelength of light measured in wavenumbers in $\mathrm{cm}^{-1}$, displayed in decreasing order of wavenumbers (Figure 2). The peaks of the spectrum, called absorbance bands, correspond to different types of bonds, specifically to vibrations of the sample's atoms. When the IR radiation passes through the sample, it makes particular bonds in the molecule absorb energy and vibrate. Then, the bonds take different forms such as scissoring, rocking, stretching, bending, etc., modes [52]. Even though different bond types result from different atoms, their vibrations have the same frequency; hence, they produce peaks at the same wavenumbers since wavenumbers are directly proportional to frequencies. Moreover, with the exception of optical isomers, no two molecules share the same IR spectrum [53]. This way, with the use of correlation tables from spectra recorded from known substances, a sample's identity, and also its structure and molecular composition, can be revealed.

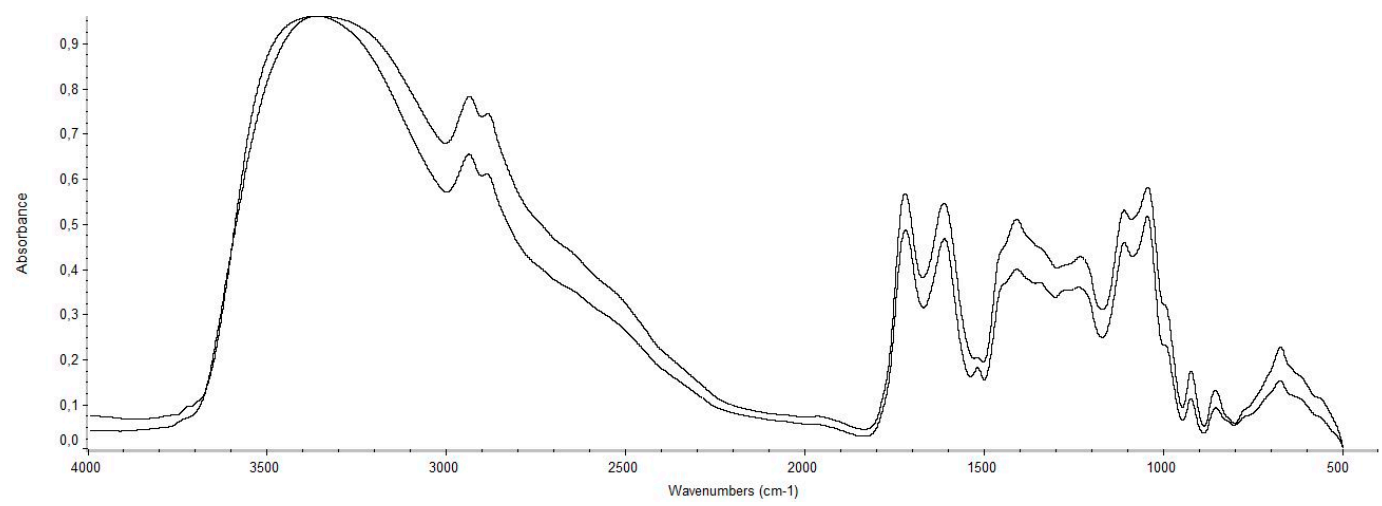

Figure 2. Typical FT-IR spectra obtained from wine samples (red and white wines from Crete, Greece).

A typical spectrum is recorded from 4000 to $400 \mathrm{~cm}^{-1}$ and contains information on the types of bonds and their vibrations. Most of the information is provided by the region 1500 to $400 \mathrm{~cm}^{-1}$, called the "fingerprint" region, and for this reason it is the one mostly used for the discrimination of food products [18]. Normally, the whole spectral range is usually recorded for every sample, but for statistical analyses, smaller regions can be used. Phenolic groups are depicted in the peak found around 1500-1400 $\mathrm{cm}^{-1}$, sugar functional groups at 1200-950 $\mathrm{cm}^{-1}$, and esters, carboxylic acid and carbonyl groups at 1618 and $1407 \mathrm{~cm}^{-1}$ [54]. Even if only the fingerprint region, which amounts to one-half of the spectrum, is used for discrimination purposes and even if it contains an ostensibly low number of peaks or absorption bands, the use of chemometrics is the key for further analysis.

For FT-IR spectroscopy, the use of chemometrics is imperative. Indeed, all FT-IR instruments come with a built-in software that is used for spectra interpretation and for statistical analyses as the volume of information contained in an IR spectrum is considerably large. External statistical packages can also be successfully used; however, not all can handle the extremely large volume of data produced after exporting a spectrum in formats that store data in tables.

The optimum steps of statistical analysis contain firstly an exploratory step, typically performed by PCA analysis, which gives information on potentially existing trends in the dataset. PCA's advantage is that it reduces the number of variables, replacing them by a new set of variables known as principal components. After PCA, supervised methods can be performed, in order to check if the samples can be grouped according to the desired feature, i.e., according to their place of origin.

Supervised methods need a set of known sample data for training purposes, which are essential for the building of the model, and then a second set of new, unknown sample data to evaluate the model's efficiency and accuracy. Usually, a third set of data, part of the training dataset, is also used for validation purposes, this way assessing the goodness of fit of the model [33]. It is evident that in order for three sets of data to form, a large number of samples is needed. The number of samples not only affects the quality of the developed model, but is also necessary to avoid overfitting problems, since IR spectra result in a large number of variables that may exceed the number of samples. This problem is 
common when building models with spectral data; it can, however, also be overcome with techniques such as stepwise regression [27].

\section{FT-IR as a Traceability and Authenticity Tool}

FT-IR has become a valuable tool in wine analysis, since it has been successfully used not only to detect and quantify key wine compounds but also to classify wines and monitor their fermentation or aging process [55]. Its ability to record the chemical "fingerprint" of wine has made it extremely useful in quality control, as it can serve as an indicator of a wine's status in terms of quality and origin.

\subsection{Traceability}

In traceability, FT-IR has aided with peripheral analyses, such as the authentication of labels from expensive and prestigious wines [56]. However, a fingerprinting system has also been developed which is able to confirm whether a wine's composition has changed during transport and processing by scanning samples at control points with mid-IR spectrophotometers and then using a similarity index method to classify them [57]. With this method, $98 \%$ of the wines were correctly classified.

\subsection{Authenticity}

In authenticity, FT-IR is becoming an invaluable tool as it can provide classifications based on a wide number of parameters and is extensively used either through attenuated total reflectance (ATR), diffuse reflectance Fourier transform (DRIFT) or transmission techniques.

\subsubsection{Origin}

FT-IR has been successful in differentiating Shiraz wines from different Australian regions (98 wines, 95.3 correct classification with SIMCA), Sauvignon blanc wines from Australia and New Zealand (64 wines, $86 \%$ correct classification with partial least squares discriminant analysis models), Cabernet Sauvignon wines from Australia, Chile and China (540 wines, 97\%, 97\% and 92\% correct classification for each country, respectively, with SIMCA) and also for South Australian Chardonnay grapes from different geographical indications (83\% correct classification with PLS) and for wines from different zones from the same appellation (La Mancha), which requires a higher degree of differentiation (120 wines, 73\% correct classification with SIMCA) [50,58-61]. The spectral region used for origin authentication was mostly from 1500 to $800 \mathrm{~cm}^{-1}$. In the study classifying Sauvignon blanc from Australia and New Zealand, the highest PCA eigenvectors (eigenvector is the direction of the vector defining the new feature space on PCA) were observed around $1045-1080 \mathrm{~cm}^{-1}$, related to the C-OH found in glycerol, ethanol, glucose and fructose; around 1454-1419 $\mathrm{cm}^{-1}$, where organic acids and aldehydes absorb; with a peak around $1268 \mathrm{~cm}^{-1}$ which related to aromatic groups [50].

\subsubsection{Grape Variety}

Red grape varieties have extensively been analyzed and showed very good classification results. White wines, for which clear links between composition and quality have been made, are considered more difficult in classification, even more so because they lack substantial amounts of phenolic compounds on which most of the classification analyses are based. Research, however, has shown successful discrimination results for red wines from Xinomavro, Agiorgitiko and Merlot grapes grown in different regions in Greece with the ATR technique (34 samples, between 84-99\% correct classification for each sample by comparison with libraries from OMNIC software, v.7.3, Thermo Electron Corporation, Waltham, MA, USA) and also for red (Kotsifali and Mandilari) and white wines (Vilana and Dafni) from the same origin (Crete, Greece) with both ATR and the transmittance technique (88 samples for the ATR technique, complete discrimination for red and white with LDA, 154 samples for the transmittance technique, 82\% validation with LDA) [62-64]. In all three studies, samples contained wines maturing both in stainless steel tanks and in wooden barrels, in order to 
increase sample variability. Young wines (400 samples) from South African red and white cultivars were correctly discriminated as well; in a study that used gas chromatography coupled with FT-IR and chemometrics, however, the highest percentage of correct classification was based only on IR spectra analysis (98.3\%, LDA). However, in this study, wines were young, without oak maturation or aging in order to minimize variability [65]. FT-IR along with artificial neural networks (ANN) also provided satisfactory results in the discrimination of five grape varieties, red and white, used for the protected designation of origin (PDO) in Vino de calidad de Cangas in Spain [66], while varietal discrimination has been successful using grapes and grape juice (from the white varieties Chardonnay and Riesling) as well [67]. The spectral regions used for variety discrimination with the ATR technique performed by Tarantilis et al. (2008) were in the region of $1800-900 \mathrm{~cm}^{-1}$, as in this area the fingerprint region is included. Absorptions in this region correspond to antisymmetric in-plane bending of - $\mathrm{CH} 3$, deformation of - $\mathrm{CH} 2$, symmetric in-plane bending of $-\mathrm{CH} 3, \mathrm{CH}$ bending, $\mathrm{CH}_{2}$ wagging, in-plane bending of $\mathrm{O}-\mathrm{H}$ and stretching vibration of $\mathrm{C}-\mathrm{O}$, plus it is the region where the phenyl nucleus $(\mathrm{C}=)$ absorbs [62]. For the classification of Cretan wines with the transmittance technique, the region selected for analysis was from 1300 to $900 \mathrm{~cm}^{-1}$, which is the area where the grape-derived tannins occur [63], while with the ATR technique, the region used was the fingerprint region $\left(1800-900 \mathrm{~cm}^{-1}\right)$ [64]. For the discrimination of grape juices, the most important peaks seem to be the peak of fructose at $1070 \mathrm{~cm}^{-1}$, water at $780 \mathrm{~cm}^{-1}$ and the peak of phenolic compounds at $1256 \mathrm{~cm}^{-1}$ [67].

\subsubsection{Type and Length of Maturation}

Discrimination of wines maturing in stainless steel vats or in contact with different types of wood (French and American oak, acacia and chestnut) in the form of a barrel or as sticks has recently been successful in samples from Greek wines (154 samples, LDA) [63]. The IR region selected for the discrimination was from 1800 to $1500 \mathrm{~cm}^{-1}$ where hydrolyzable tannins or wood tannins absorb. Correct discrimination reached $96 \%$, although the external validation set reached only $52 \%$ of correct classification, probably due to the high variability in tannin concentrations. However, wine samples maturing in acacia and chestnut barrels were completely discriminated, with $82 \%$ and $100 \%$ correct classification in the validation sets, respectively. In the same experiment, samples were correctly classified based on the length of contact with the wine container by $100 \%$ in the training and test sets, and $93 \%$ for the validation set. The region used for the analyses was the area from $1800-1500 \mathrm{~cm}^{-1}$.

\subsubsection{Vintage}

The vintage is a complex parameter, chemically manifested indirectly through changes in wine composition due to a number of factors such as the weather, the time of harvest, the winemaking conditions, etc. Vintage authentication with FT-IR can also be performed indirectly, by measuring the "chemical wine" age as defined by Somers in 1977 [68]. FT-IR has successfully been used to predict chemical age indexes i and ii by PLS regression modeling [69]. Recently, a study examined the feasibility of using FT-IR to define vintage, giving encouraging results, as the discrimination was complete for wines aged over six years [70].

\subsubsection{Adulteration/Taints}

Millennials' interest in wine has prompted winemakers to try and meet the generation's demands, since this is the consumer group currently in the spotlight [71]. Among others, this means an elevated demand for ethically produced food with as few chemicals as possible, hence increased production of organic and biodynamic wines that need to be authenticated [72]. FT-IR has been shown to be able to correctly classify more than $85 \%$ of wines belonging to organic or nonorganic systems in an experiment on 172 red and white wine samples from 13 different regions in Australia [73].

Moreover, reduced quality due to taints such as smoke, a recurring problem in wines coming from Australia, for example, which has been hit with extremely destructive bushfires over the last few years, can be also detected with FT-IR. Indeed, in 2012, LDA models helped correctly classify 70\% of 
smoke-tainted wines, revealing the potential of mid-IR spectroscopy combined with chemometrics in rapid quality screenings regarding this wine fault $[74,75]$.

\section{Prospects and Challenges}

It is evident that FT-IR spectroscopy is a successful tool in wine authentication and traceability. However, most analyses focus on one or several parameters of interest which in turn increase based on consumer and market demands. Future research should be based on typical authentication needs that still require sophisticated analyses such as the detection of chaptalization-an illegal sugar addition to wine-but also need to follow modern production practices and deal with contemporary techniques such as the use of genetically modified yeasts and the possibility of discriminating the wines produced.

FT-IR's flexibility allows remote detection, so new styles are emerging such as open path FT-IR that can detect volatiles without a gas cell (which is needed in gas phase infrared spectroscopy) and which was recently used to detect volatile compounds in grapes and vinegars [75]. This provides new possibilities in wine research, where quality is inseparably connected to the volatile profile.

The biggest and most imperative need in the search for more effective and complete classifications, however, is the construction of a wine databank which would help minimize the variability issues all studies based on analyses with large spectral data face.

\section{Conclusions}

FT-IR spectroscopy continuingly gains popularity in wine research, as it provides a simple, fast and cost-effective way to analyze different components even in low concentrations without the need for chemicals or preparatory steps. It can be a valuable tool in wine authentication and traceability, provided that a large set of samples is analyzed or a database constructed by various wine samples is used for comparison reasons. The optimization of algorithms used in chemometrics can boost the performance of FT-IR-based models and provide more efficient classifications. Finally, the renewed interest in the examination of the volatile profile with the use of FT-IR and chemometrics could be implemented in wine authentication in order to amplify the fingerprint provided.

Author Contributions: Conceptualization and writing, M.B.; investigation, C.P. and S.K.; bibliography research, P.A.T.; review and editing, S.K., C.P. and P.A.T. All authors have read and agreed to the published version of the manuscript.

Funding: This research received no external funding.

Conflicts of Interest: The authors declare no conflict of interest.

\section{References}

1. Beverland, M. The "real thing": Branding authenticity in the luxury wine trade. J. Bus. Res. 2006, 59, 251-258. [CrossRef]

2. Aytaç, B.; Van Hoang, T.H.; Mandou, C. Wine: To drink or invest in? A study of wine as an investment asset in French portfolios. Res. Int. Bus. Financ. 2016, 36, 591-614. [CrossRef]

3. Sung, B.; Crawford, R.; Teah, M.; Stankovic, M.; Phau, I. The "timber box" effect for premium wines. J. Retail. Consum. Serv. 2020, 54, 102034. [CrossRef]

4. Yue, C.; Marette, S.; Beghin, J.C. How to promote quality perception: Brand advertising or geographical indication? Nontariff Meas. Int. Trade 2016, 339-364.

5. Markham, D. 1855: A History of the Bordeaux Classification; Wiley: Hoboken, NJ, USA, 1997.

6. Herrero-Latorre, C.; Barciela-García, J.; García-Martín, S.; Peña-Crecente, R.M. Detection and quantification of adulterations in aged wine using RGB digital images combined with multivariate chemometric techniques. Food Chem. X 2019, 3, 100046. [CrossRef] [PubMed]

7. Bonanno, A.; Bimbo, F.; Costanigro, M.; Lansink, A.O.; Viscecchia, R. Credence attributes and the quest for a higher price-A hedonic stochastic frontier approach. Eur. Rev. Agric. Econ. 2019, 46, 1-30. [CrossRef]

8. Palade, M.; Popa, M. Wine traceability and authenticity-A literature review. Ser. F Biotechnol. 2014, 18, 226-233. 
9. Arnó, J.; Martínez Casasnovas, J.A.; Ribes Dasi, M.; Rosell, J.R. Review. Precision viticulture. Research topics, challenges and opportunities in site-specific vineyard management. Span. J. Agric. Res. 2009, 7, 779. [CrossRef]

10. Van Leeuwen, C.; Seguin, G. The concept of terroir in viticulture. J. Wine Res. 2006, 17, 1-10. [CrossRef]

11. Gonzálvez, A.; Llorens, A.; Cervera, M.L.; Armenta, S.; de la Guardia, M. Elemental fingerprint of wines from the protected designation of origin Valencia. Food Chem. 2009, 112, 26-34. [CrossRef]

12. Baxter, M.J.; Crews, H.M.; Dennis, M.J.; Goodall, I.; Anderson, D. The determination of the authenticity of wine from its trace element composition. Food Chem. 1997, 60, 443-450. [CrossRef]

13. Galgano, F.; Favati, F.; Caruso, M.; Scarpa, T.; Palma, A. Analysis of trace elements in southern Italian wines and their classification according to provenance. LWT Food Sci. Technol. 2008, 41, 1808-1815. [CrossRef]

14. Valentin, L.; Barroso, L.P.; Barbosa, R.M.; de Paulo, G.A.; Castro, I.A. Chemical typicality of South American red wines classified according to their volatile and phenolic compounds using multivariate analysis. Food Chem. 2020, 302, 125340. [CrossRef] [PubMed]

15. Langlois, J.; Dacremont, C.; Peyron, D.; Valentin, D.; Dubois, D. Lexicon and types of discourse in wine expertise: The case of vin de garde. Food Qual. Prefer. 2011, 22, 491-498. [CrossRef]

16. Kyraleou, M.; Kallithraka, S.; Chira, K.; Tzanakouli, E.; Ligas, I.; Kotseridis, Y. Differentiation of Wines Treated with Wood Chips Based on Their Phenolic Content, Volatile Composition, and Sensory Parameters. J. Food Sci. 2015, 80, C2701-C2710. [CrossRef]

17. Sagratini, G.; Maggi, F.; Caprioli, G.; Cristalli, G.; Ricciutelli, M.; Torregiani, E.; Vittori, S. Comparative study of aroma profile and phenolic content of Montepulciano monovarietal red wines from the Marches and Abruzzo regions of Italy using HS-SPME-GC-MS and HPLC-MS. Food Chem. 2012, 132, 1592-1599. [CrossRef]

18. Abdul, S.; Boli, G.; Xiaowen, Z.; Hussain, I.; Yimin, W. Recent development in the application of analytical techniques for the traceability and authenticity of food of plant origin. Microchem. J. 2020, 152, 104295.

19. Arfelli, G.; Sartini, E.; Corzani, C.; Fabiani, A.; Natali, N.; Science, F. Impact of Wooden Barrel Storage on the Volatile Composition. Food Sci. Technol. Int. 2007, 13, 293-299. [CrossRef]

20. Dinca, O.R.; Ionete, R.E.; Costinel, D.; Geana, I.E.; Popescu, R.; Stefanescu, I.; Radu, G.L. Regional and Vintage Discrimination of Romanian Wines Based on Elemental and Isotopic Fingerprinting. Food Anal. Methods 2016, 9, 2406-2417. [CrossRef]

21. Godelmann, R.; Fang, F.; Humpfer, E.; Schütz, B.; Bansbach, M.; Schäfer, H.; Spraul, M. Targeted and Nontargeted Wine Analysis by $1 \mathrm{H}$ NMR Spectroscopy Combined with Multivariate Statistical Analysis. Differentiation of Important Parameters: Grape Variety, Geographical Origin, Year of Vintage. J. Agric. Food Chem. 2013, 61, 5610-5619. [CrossRef]

22. Cabrita, M.J.; Martins, N.; Barrulas, P.; Garcia, R.; Dias, C.B.; Pérez-Álvarez, E.P.; Costa Freitas, A.M.; Garde-Cerdán, T. Multi-element composition of red, white and palhete amphora wines from Alentejo by ICPMS. Food Control 2018, 92, 80-85. [CrossRef]

23. Azcarate, S.M.; Martinez, L.D.; Savio, M.; Camiña, J.M.; Gil, R.A. Classification of monovarietal Argentinean white wines by their elemental profile. Food Control 2015, 57, 268-274. [CrossRef]

24. Peris, M.; Escuder-Gilabert, L. Electronic noses and tongues to assess food authenticity and adulteration. Trends Food Sci. Technol. 2016, 58, 40-54. [CrossRef]

25. Oliver, S.G.; Winson, M.K.; Kell, D.B.; Baganz, F. Systematic functional analysis of the yeast genome. Trends Biotechnol. 1998, 16, 373-378. [CrossRef]

26. Genisheva, Z.; Quintelas, C.; Mesquita, D.P.; Ferreira, E.C.; Oliveira, J.M.; Amaral, A.L. New PLS analysis approach to wine volatile compounds characterization by near infrared spectroscopy (NIR). Food Chem. 2018, 246, 172-178. [CrossRef] [PubMed]

27. Hu, L.; Yin, C.; Ma, S.; Liu, Z. Rapid detection of three quality parameters and classification of wine based on Vis-NIR spectroscopy with wavelength selection by ACO and CARS algorithms. Spectrochim. Acta Part A Mol. Biomol. Spectrosc. 2018, 205, 574-581. [CrossRef]

28. Véstia, J.; Barroso, J.M.; Ferreira, H.; Gaspar, L.; Rato, A.E. Predicting calcium in grape must and base wine by FT-NIR spectroscopy. Food Chem. 2019, 276, 71-76. [CrossRef]

29. Versari, A.; Laurie, V.F.; Ricci, A.; Laghi, L.; Parpinello, G.P. Progress in authentication, typification and traceability of grapes and wines by chemometric approaches. Food Res. Int. 2014, 60, 2-18. [CrossRef]

30. Fabani, M.P.; Ravera, M.J.A.; Wunderlin, D.A. Markers of typical red wine varieties from the Valley of Tulum (San Juan-Argentina) based on VOCs profile and chemometrics. Food Chem. 2013, 141, 1055-1062. [CrossRef] 
31. Monakhova, Y.B.; Tsikin, A.M.; Mushtakova, S.P. Independent components analysis as an alternative to principal component analysis and discriminant analysis algorithms in the processing of spectrometric data. J. Anal. Chem. 2015, 70, 1055-1061. [CrossRef]

32. Da Costa, N.L.; Castro, I.A.; Barbosa, R. Classification of Cabernet Sauvignon from Two Different Countries in South America by Chemical Compounds and Support Vector Machines. Appl. Artif. Intell. 2016, 30, 679-689. [CrossRef]

33. Jiménez-Carvelo, A.M.; González-Casado, A.; Bagur-González, M.G.; Cuadros-Rodríguez, L. Alternative data mining/machine learning methods for the analytical evaluation of food quality and authenticity-A review. Food Res. Int. 2019, 122, 25-39. [CrossRef] [PubMed]

34. García-Beneytez, E.; Revilla, E.; Cabello, F. Anthocyanin pattern of several red grape cultivars and wines made from them. Eur. Food Res. Technol. 2002, 215, 32-37. [CrossRef]

35. González-Neves, G.; Franco, J.; Barreiro, L.; Gil, G.; Moutounet, M.; Carbonneau, A. Varietal differentiation of Tannat, Cabernet-Sauvignon and Merlot grapes and wines according to their anthocyanic composition. Eur. Food Res. Technol. 2007, 225, 111-117. [CrossRef]

36. Castillo-Muñoz, N.; Gómez-Alonso, S.; García-Romero, E.; Hermosín-Gutiérrez, I. Flavonol profiles of Vitis vinifera red grapes and their single-cultivar wines. J. Agric. Food Chem. 2007, 55, 992-1002. [CrossRef]

37. Makris, D.P.; Kallithraka, S.; Mamalos, A. Differentiation of young red wines based on cultivar and geographical origin with application of chemometrics of principal polyphenolic constituents. Talanta 2006, 70, 1143-1152. [CrossRef]

38. Pavloušek, P.; Kumšta, M. Authentication of riesling wines from the Czech Republic on the basis of the non-flavonoid phenolic compounds. Czech J. Food Sci. 2013, 31, 474-482. [CrossRef]

39. Bellomarino, S.A.; Conlan, X.A.; Parker, R.M.; Barnett, N.W.; Adams, M.J. Geographical classification of some Australian wines by discriminant analysis using HPLC with UV and chemiluminescence detection. Talanta 2009, 80, 833-838. [CrossRef]

40. Basalekou, M.; Kallithraka, S.; Tarantilis, P.A.; Kotseridis, Y.; Pappas, C. Ellagitannins in wines: Future prospects in methods of analysis using FT-IR spectroscopy. LWT 2019, 101, 48-53. [CrossRef]

41. Seeber, R.; Sferlazzo, G.; Leardi, R.; Dalla Serra, A.; Versini, G. Multivariate Data Analysis in Classification of Musts and Wines of the Same Variety According to Vintage Year. J. Agric. Food Chem. 1991, 39, 1764-1769. [CrossRef]

42. Kruzlicova, D.; Mocak, J.; Balla, B.; Petka, J.; Farkova, M.; Havel, J. Classification of Slovak white wines using artificial neural networks and discriminant techniques. Food Chem. 2009, 112, 1046-1052. [CrossRef]

43. Perestrelo, R.; Barros, A.S.; Câmara, J.S.; Rocha, S.M. In-depth search focused on furans, lactones, volatile phenols, and acetals as potential age markers of Madeira wines by comprehensive two-dimensional gas chromatography with time-of-flight mass spectrometry combined with solid phase microextraction. J. Agric. Food Chem. 2011, 59, 3186-3204. [CrossRef] [PubMed]

44. Jakubowski, N.; Brandt, R.; Stuewer, D.; Eschnauer, H.R.; Görtges, S. Analysis of wines by ICP-MS: Is the pattern of the rare earth elements a reliable fingerprint for the provenance? Fresenius. J. Anal. Chem. 1999, 364, 424-428. [CrossRef]

45. Aceto, M.; Robotti, E.; Oddone, M.; Baldizzone, M.; Bonifacino, G.; Bezzo, G.; Di Stefano, R.; Gosetti, F.; Mazzucco, E.; Manfredi, M.; et al. A traceability study on the Moscato wine chain. Food Chem. 2013, 138, 1914-1922. [CrossRef] [PubMed]

46. Zou, J.-F.; Peng, Z.-X.; Du, H.-J.; Duan, C.-Q.; Reeves, M.J.; Pan, Q.-H. Elemental Patterns of Wines, Grapes, and Vineyard Soils from Chinese Wine-Producing Regions and Their Association. Am. J. Enol. Vitic. 2012, 63, 232-240. [CrossRef]

47. Catarino, S.; Madeira, M.; Monteiro, F.; Rocha, F.; Curvelo-Garcia, A.S.; de Sousa, R.B. Effect of Bentonite Characteristics on the Elemental Composition of Wine. J. Agric. Food Chem. 2008, 56, 158-165. [CrossRef]

48. Nicolini, G.; Larcher, R.; Pangrazzi, P.; Bontempo, L. Changes in the contents of micro- and trace-elements in wine due to winemaking treatments. Vitis 2004, 43, 41-45.

49. Publications Office of the European Union. Commission Regulation (EC) No 2347/91 of 29 July 29 Collection of Samples of Wine Products for the Purposes of Cooperation between Member States and for the Analysis by Nuclear Magnetic Resonance, Including Analysis for the Purposes of the Community Datab; Publications Office of the European Union: Brussels, Belgium, 1991; Volume 214. 
50. Cozzolino, D.; Cynkar, W.U.; Shah, N.; Smith, P.A. Can spectroscopy geographically classify Sauvignon Blanc wines from Australia and New Zealand? Food Chem. 2011, 126, 673-678. [CrossRef]

51. Wartewig, S. Fourier Transform Technique. In IR and Raman Spectroscopy; Wiley: Hoboken, NJ, USA, 2003; pp. 35-51.

52. Bureau, S.; Cozzolino, D.; Clark, C.J. Contributions of Fourier-transform mid infrared (FT-MIR) spectroscopy to the study of fruit and vegetables: A review. Postharvest Biol. Technol. 2019, 148, 1-14. [CrossRef]

53. El-Ahmady, S.H.; Ashour, M.L. 24-Advances in Testing for Adulteration of Food Supplements. In Woodhead Publishing Series in Food Science, Technology and Nutrition; Downey, G.B.T.-A., Ed.; Woodhead Publishing: Cambridge, UK, 2016; pp. 667-699.

54. Uríčková, V.; Sádecká, J. Determination of geographical origin of alcoholic beverages using ultraviolet, visible and infrared spectroscopy: A review. Spectrochim. Acta Part A Mol. Biomol. Spectrosc. 2015, 148, 131-137. [CrossRef]

55. Ferreiro-González, M.; Ruiz-Rodríguez, A.; Barbero, G.F.; Ayuso, J.; Álvarez, J.A.; Palma, M.; Barroso, C.G. FT-IR, Vis spectroscopy, color and multivariate analysis for the control of ageing processes in distinctive Spanish wines. Food Chem. 2019, 277, 6-11. [CrossRef] [PubMed]

56. Grijalba, N.; Maguregui, M.; Unceta, N.; Morillas, H.; Médina, B.; Barrio, R.J.; Pécheyran, C. Direct non-invasive molecular analysis of packaging label to assist wine-bottle authentication. Microchem. J. 2020, 154, 104564. [CrossRef]

57. Bevin, C.J.; Fergusson, A.J.; Perry, W.B.; Janik, L.J.; Cozzolino, D. Development of a Rapid "Fingerprinting" System for Wine Authenticity by Mid-infrared Spectroscopy. J. Agric. Food Chem. 2006, 54, 9713-9718. [CrossRef]

58. Riovanto, R.; Cynkar, W.U.; Berzaghi, P.; Cozzolino, D. Discrimination between Shiraz wines from different Australian regions: The role of spectroscopy and chemometrics. J. Agric. Food Chem. 2011, 59, 10356-10360. [CrossRef]

59. Urbano Cuadrado, M.; Luque De Castro, M.D.; Gómez-Nieto, M.A. Study of spectral analytical data using fingerprints and scaled similarity measurements. Anal. Bioanal. Chem. 2005, 381, 953-963. [CrossRef] [PubMed]

60. Gambetta, J.M.; Cozzolino, D.; Bastian, S.E.P.; Jeffery, D.W. Classification of Chardonnay Grapes According to Geographical Indication and Quality Grade Using Attenuated Total Reflectance Mid-infrared Spectroscopy. Food Anal. Methods 2019, 12, 239-245. [CrossRef]

61. Hu, X.Z.; Liu, S.Q.; Li, X.H.; Wang, C.X.; Ni, X.L.; Liu, X.; Wang, Y.; Liu, Y.; Xu, C.H. Geographical origin traceability of Cabernet Sauvignon wines based on Infrared fingerprint technology combined with chemometrics. Sci. Rep. 2019, 9, 1-9. [CrossRef] [PubMed]

62. Tarantilis, P.A.; Troianou, V.E.; Pappas, C.S.; Kotseridis, Y.S.; Polissiou, M.G. Differentiation of Greek red wines on the basis of grape variety using attenuated total reflectance Fourier transform infrared spectroscopy. Food Chem. 2008, 111, 192-196. [CrossRef]

63. Basalekou, M.; Pappas, C.; Tarantilis, P.; Kotseridis, Y.; Kallithraka, S. Wine authentication with Fourier Transform Infrared Spectroscopy: A feasibility study on variety, type of barrel wood and ageing time classification. Int. J. Food Sci. Technol. 2017, 52, 1307-1313. [CrossRef]

64. Basalekou, M.; Strataridaki, A.; Pappas, C.; Tarantilis, P.A.; Kotseridis, Y.; Kallithraka, S. Authenticity determination of greek-cretan mono-varietal white and red wines based on their phenolic content using attenuated total reflectance fourier transform infrared spectroscopy and chemometrics. Curr. Res. Nutr. Food Sci. 2016, 4. [CrossRef]

65. Louw, L.; Roux, K.; Tredoux, A.; Tomic, O.; Naes, T.; Nieuwoudt, H.H.; van Rensburg, P. Characterization of Selected South African Young Cultivar Wines Using FTMIR Spectroscopy, Gas Chromatography, and Multivariate Data Analysis. J. Agric. Food Chem. 2009, 57, 2623-2632. [CrossRef] [PubMed]

66. Murru, C.; Chimeno-Trinchet, C.; Díaz-García, M.E.; Badía-Laíño, R.; Fernández-González, A. Artificial Neural Network and Attenuated Total Reflectance-Fourier Transform Infrared Spectroscopy to identify the chemical variables related to ripeness and variety classification of grapes for Protected. Designation of Origin wine production. Comput. Electron. Agric. 2019, 164, 104922. [CrossRef]

67. Cozzolino, D.; Cynkar, W.; Shah, N.; Smith, P. Varietal Differentiation of Grape Juice Based on the Analysis of Near- and Mid-infrared Spectral Data. Food Anal. Methods 2012, 5, 381-387. [CrossRef] 
68. Somers, T.C.; Evans, M.E. Spectral evaluation of young red wines: Anthocyanin equilibria, total phenolics, free and molecular $\mathrm{SO}_{2}$, chemical age. J. Sci. Food Agric. 1977, 28, 279-287. [CrossRef]

69. Basalekou, M.; Pappas, C.; Kotseridis, Y.; Tarantilis, P.A.; Kontaxakis, E.; Kallithraka, S. Red wine age estimation by the alteration of its color parameters: Fourier transform infrared spectroscopy as a tool to monitor wine maturation time. J. Anal. Methods Chem. 2017, 2017, 1-9. [CrossRef] [PubMed]

70. Geana, E.I.; Ciucure, C.T.; Apetrei, C.; Artem, V. Application of spectroscopic UV-Vis and FT-IR screening techniques coupled with multivariate statistical analysis for red wine authentication: Varietal and vintage year discrimination. Molecules 2019, 24, 4166. [CrossRef]

71. Lancaster, L.C.; Stillman, D. When Generations Collide: Who They Are, Why They Clash, How to Solve the Generational Puzzle at Work; HarperBusiness: New York, NY, USA, 2003.

72. Rodrigues, H.; Parr, W.V. Contribution of cross-cultural studies to understanding wine appreciation: A review. Food Res. Int. 2019, 115, 251-258. [CrossRef]

73. Cozzolino, D.; Holdstock, M.; Dambergs, R.G.; Cynkar, W.U.; Smith, P.A. Mid infrared spectroscopy and multivariate analysis: A tool to discriminate between organic and non-organic wines grown in Australia. Food Chem. 2009, 116, 761-765. [CrossRef]

74. Fudge, A.L.; Wilkinson, K.L.; Ristic, R.; Cozzolino, D. Classification of Smoke Tainted Wines Using Mid-Infrared Spectroscopy and Chemometrics. J. Agric. Food Chem. 2012, 60, 52-59. [CrossRef]

75. Dong, D.; Zheng, W.; Wang, W.; Zhao, X.; Jiao, L.; Zhao, C. A new volatiles-based differentiation method of Chinese spirits using longpath gas-phase infrared spectroscopy. Food Chem. 2014, 155, 45-49. [CrossRef]

(C) 2020 by the authors. Licensee MDPI, Basel, Switzerland. This article is an open access article distributed under the terms and conditions of the Creative Commons Attribution (CC BY) license (http://creativecommons.org/licenses/by/4.0/). 